\title{
NUESTRA EXPERIENCIA CON LA QUIMIOTERAPIA SULFAMIDADA EN EL TRATAMIENTO DE LAS OTITIS MEDIAS AGUDAS SUPURADAS DE LA INFANCIA
}

\author{
Por el Dt. AUGUSTO latorke AgÜero \\ Servicio de O. R. L. del Hospitsl Arriarán. \\ Jefe: Dr. M. Parada.
}

A la ola de entusiasmo y de optimismo que despertó en un comienzo el uso de la Quimioterapia en el tratamiento de las otitis agudas supuradas, ha seguido, en estos últimos años. un marcado escepticismo por parte de numerosos autores extranjeros. y actualmente sus resultados son muy discuridos.

Una de las comunicaciones más optimistas a este resp?:to. es tal vez la hecha en el año 1938 por los británicos Horan y French, quienes, en un total de 155 casos de otitis agudas tratadas por la Quimioterapia, tuvieron sólo 7 mastoiditis. O sea, un porcentaje de $4.5 \%$, siendo que, dentro del mismo matio hospitalario, en los cuatro años anteriores al uso de la Quimicterapia, las mastoiditis complicaban el $22.7 \%$ de las otitis agudas.

Otra estadistica favorable, es la de los nortemmericanos Braun y Bigler, publicada en 1941, quienes trataron un grupo de 222 pacientes con Quimioterapia, y otro grupo de control de 203 enfermos, por los procedimientos corriertes sin Quimioterapia. En el primer grupo. la duración media del proceso aural fué de 15 días y sólo hubo un $1,8 \%$ de complicaciones mastoídeas. En el grupo sin Quimioterapia la duración media del proceso ótico fué de 24 dias y las complicaciomes mastoideas se presentaron en un $5.9 \%$ de los casos.

En cambio, hay orras estadísticas como la de los norteamericanos Bilchick y O'Kane, que demuestran que la Quimioterapia no disminuye en absoluto las complicaciones mastoídeas en las otitis agudas. Estos autores encontraron que en 55 casos tratados con Quimioterapia (sulfanilamida), en $9(16 \%)$ hubo que recurrir al vaciamiento mastoideo, y en cambic, en 
48 asos en que no se usó esta terapéutica, sólo en $5(10,4 \%)$ fué necesaria la mastoidectomía.

Naturalmente: que a todos estos resultados puede hacétsele la seria objeción de que la mayor o menor abundancia de ccroplicaciones mastoídeas puede set simplemente función da la rirulencia de los gérmenes, que puede experimentar grandes variaciones de un año a otro. como lo han comprobado, por ejemplo, Guilermin y Mygayron, durante el invierno de 1930-1931 en París, darante el cual el número de complicaciones mastoídeas en las otitis agudas, fué cuatro vezes más elevado que en los años anteriores.

Actuainiente, muchos autores extranjeros como Mariani, Babcock, etc. (citados por Kopetzky), aconsejan, incluso, no usar la Quimioterapia co las otitis agudas y reservarla sólo fara los casos con complicaciones graves, meníngeas o vascuares en las cuales tiene una acción indiscurible, para evitat el peligro derivado de la acción enmascarante de estas drogas.

La acción. enmascarante de la Quimioterapia en los procesos mastódeos agudos, ha dado margen últimamente a numerosas publicaciones lcomo ser las de Ombredanne en Francia y la de Maybaum. Snyder y Coleman. en los Estades Unidos. etc.), que han contribuído a moderat en grin parte el uso rutinario de estos preparados. Esta acción enmasiarante censiste, como ustedes saben, en la desaparición, bajo la influencia del tratamiento quimioterápico, de los signos alarmantes, tales como fiebre, otorrea, dolor a la palpación de la apófisis mastcides, etc., a pesar de lo cual el proceso necrótico continúa su evolución en forma solapada hasta producir una grave complicación meningea o intractaneana. sin que el cirujano lo sospeche por la falta de signos exteriores.

La conducta más lógica tal yez para la mayoria de los esfecialistas, es usar la Quimioterapia simultáneamente o-com: un complemento del tratamiento quirúrgico, opinión que $\mathrm{com}^{-}$ parten especialistas tan eminentes como Ombredanne en Francia y Kcpetzky en los Estados Unidos.

Ante esta diversidad de opiniones acerca del valor de la Quimioterapia en el tratamiento de las otitis agudas. hemos querido sacar nuestras propias conclusiones en forma absolutamente imparcial y sin dejarnos impresionar por el convencimiento general que existe en nuestro ambiente, relativo a ta gran eficacia de estas drogas en el tratamiento de estos cuadros patológicos. Con este fin. siguiendo el procedimiento usado por numerosos investigadores extranjetos, hemos tratado po: Ja Quimioterapia 45 casos de otitis medias agudas supuradis. 
usando como control otro grupo de 50 enfermos tratados pot los procedimientos corrientes, sin Quimioterapia, para luege comparar los resultados.

Todos estos pacientes eran niños cuya edad fluctuaba entre 3 meses y 10 años, vistos en el Policlínico de O. R. I. de] Hospital Artiarán durante el año 1942. Las observaciones fueron seguidas en muchos casos durante varios meses.

En ei grupo de enfermos tratados con Quimioterapia sólo incluímos aquellos casos con otorrea menor de 8 dias. para cvitar la posibilidad de que existieran focos óseos necróticos o supurados. Estos procesos óseos destructivos a nivel de la apófisis mastoides, no se constituyen, por lo general, sino a partir de la tercera semana de evolución de la otitis, y en estos casos se ha demostrado que la acción de la Quimioterapia es ya prácticamente nula y sólo contribuye a enmascarar las jesiones.

Los compuestos usados por nosotros en el tratamiento quimicterápico fueron la sulfanimalida (Aseptil, Acetilina). Ia sulfapiridina (Dagénan) y el sulfatiazol.

Sabemos, como se ha demostrado experimentalmente, que la acción de estos preparados es más enérgica para algunos microorganismos en especial; así, por ejemplo. la sulfanilamida actuaría principalmente contra el estreptococo hemolitico. la sulfapiridina contra el pneumococo y el sulfatiazol contra et pneumococo y estafilococo. gérmenes todos éstos. habituales de las supuraciones agudas del oido medio.

En todos los casos tratados por Quimioterapia. hicimos el examen bacteriológico de la secreción ótica. por los métodos corrientes de laboratorio $y$, según el microorganismo en ccntrado, empleamos en el tratamiento el producto considerado de mayor acción contra dicho germen. Para iniciar el tratamiento sin demora. mientras esperábamos el resultado del examen bacteriológico, usamos la sulfanilamida, ya que el germen habitualmente encontrado en la secreción de las otitis agudas, es el estreptococo hemolítico. El cultivo de la secreción ótica, en los 45 casos. dió los siguientes resultados:

Desarrollo de estreptococo hemolítico al estado puro bubo en 22 casos: de estreptococo hemolítico combinado con estafiloccco dorado hemolítico, en 6 y de estreptococo hemolíco combinado al pneumococo tipo I, en 3 casos.

Desarrollo de colonias de pneumococos puros bubo en 5 casos. de los cuales 3 fueron del tipo 1 y 2 del tipo III.

Estafilococo dorado hemolítico al estado puro se encontró en 5 casos: bacilos dífteromorfos en un caso y en 3 casos no hubo desarrollo microbiano de ninguna especie. 
De modo que práctícamente en el $69 \%$ de los casos estuvo presente el estreptococo hemolítico. En todos aquellos casos de asociaciones mictobianas en que figuraba ét estreptococo hemolítico, considetamos a este germen el agente patógeno principal, siguiendo la opinión de la mayoria de los autores, ya que algunos, incluso han llegado a dudar de la acción patógena de gérmenes tales como el estafilococo dorado hemolítico, al cual consideran un saprófito desprovisto de acción patógena (Neter. Neuburger); opinión muy discutible. por lo demás.

La dosis de sulfanilamida sulfapiridina o sulfatiazol, empleada por nosotros. fué de $0.15 \mathrm{gr}$. por kilo de peso en 24 horas, repartida 5 ó 6 veces al dia. Este tratamiento 10 mantuvimos, por término medio, alrededor de 7 días, observando cuidadosamente a los enfermos, a to menos, tres veces por semana, y haciendo al $5 .^{\circ}$ o $6^{\circ}$ dia un hemograma de control. No nos fué posible. desgraciadamente, determinar la concentración sanguínea de estos preparados.

En los casos tratados sin Quimioterapia. el tratamiento empleado fué el corriente, a base de paracentesis, lavados, calor local, etc., etc.

Damos a continuación los resultados obtenidos en los dos grupos de enfermos:

En el grupo tratado sin Quimioterapia, la duración de la otorrea fluctuó entre 5 y 25 días. Pasaron a la cronicidad 5 casos y en un solo caso se presentó una complicación mastcídea que hizo necesario el vaciamiento de la apófisis mastoides.

En el grupo tratado con Quimioterapia, la duración media de la otorrea fué, aproximadamente, igual al grupo antericr. Pasaron a la cronicidad 7 casos y también en un caso fué necesaria la mastoidectomía.

Comparando estos resultados vemos que, prácticamente. con el tratamiento quimioterápico no obtuvimos ninguna ventaja sobre el tratamiento corriente. Aun más, en el caso tratado con Quimioterapia y en que hubo que recurrir al vaciamiento mastoídeo, se produjo un cuadro típico de "mastoiditis enmascarada", que nos tuvo varios días desorientados. El paciente, un niño de 7 años de edad, en cuya secreción ótica encontramos el estreptococo hemolítico, mientras estaba sometido al tratamiento con sulfanilamida, no tenía fiebre ni dolor a la presión de la apófisis mastoides y la otorrea era insignificante: pero al suspender la droga, la fiebre, otorrea abundante y dolores mastoídeos, apatecían de inmediato. Fué operado 
después de ingerir cerca de 70 gramos de sulfanilamida y sin presentar ningún síntoma alarmante en ese momento, pero 3 Ia intervención encontramos extensas lesiones óseas de la apó fisis mastoides que ya llegaban en algunos puntos a ponerse en centacto con la meninge.

En tres casos del grupo tratado con Quimioterapia. vimos aparfer una otitis aguda en el oído opuesto, al tercer-o Euarto día de iniciado el tratamiento, lo que demuestra que el valor preventivo es muy dudoso.

Después de esta exposición, la conclasión lógica debería ser que en las otitis agudas es preferible abstenerse del uso de la Quimioterapia, y reservarla sólo para las complicacioses meníngeas o vasculares, o como un complemento del tratamiento quirúrgico. Sin embargo, la acción específica reconocida de la Quimicterapia en otros cuadros infecciosos provocados también por les gérmenes habituales de las otitis (procesos pulmo: nares, génitourinarios. etc. i, hace muy difícil resistir a la tentación de usarla, y creemos, a pesar de todo, que su empleo fuede ser de utilidad, pero siempre que se haga en forma muy controlada.

Algunos especialistas extranjeros como Fowler (citado por Kopetzky) aconsejan postergar el uso de la Quimioterapia, una semana o diez días después de aparecida la otitis, $y$ si źsta no manifiesta tendencia a la curación. A nosotros nos parece preferible usarla desde el primer momento y a dosis el:vadas $(0,15 \mathrm{gr}$. por kilo de peso en 24 horas), para obtener rápidamente una alta concentración sanguínea, suspendiendo el tratamiente al tercer o cuarto día por un período de cuatro a cinco dias. $y$ en caso de no obtener una mejoria evidente. insistir con una nueva cura hecha en igual forma. Este proceder, tan diferente al usado en el tratamiento de cualquiera otra afección, es idéntico al recomendado por los argentinos Arauz, Irureta y Del Sel, y tiene la ventaja de evitar, mediante la suspensión temporal del medicamento con cada nueva cura, los graves peligros derivados de la acción enmascarante. En caso de fracasar con una segunda cura. creemos que no vale la pena insistir con la quimicterapia y debemos encarar la posibilidad de una intervención quirúrgica (vaciamiento mastoíden) y como complemento de esta intervención sí que estaría ampliamente justificada una última cuta de Quimioterapia.

La tolerancia manifestada por los niños. incluso lactantes. por la Quimioterapia, es asombrosa. Nosotros solamente, en un caso, tuvimos que suspender la medicación, en un niño da 4 años. por vómitos incoercibles. 
La Quimioterapia en las otitis del lactante estaría mayormente indicada, puesto que actúa también sobre el colibacilo. microorganismo que, en este período de la vida, exacerba su virulencia y provoca graves trastornos nutritivos con motivo de cualquiera infección paraenteral.

Es indudable que aunque actualmente, en el tratamiento de las otitis agudas, la Quimioterapia deja mucho que desear. ista será. con preparados similares más eficaces. la gran terapéutica del futuro, y bien podemos terminar citando las palabras del insigne Levaditi a este respecto:

"El porvenir es, como siempre, en materia de invención. imprevisible. Nadie puede decir ni adónde vamos ni qué sorpresas nos aguardan. Atengámonos, por el momento, al adagio "esperar y ver venir", sin abandonar ni un instante la investigación cientifica, investigación cuya serenidad no debe ser turbada por ningún sentimiento, de cualquiera naturaleza que sea".

\section{Bibliografia.}

1.-ARAUZ. IRURETA y DEL SEL. - "Consideraciones sobre la quimiotexapia suffamidica en nariz. garganta y oidos". Analei de $O$. R. L. del Uruguay, 1940. T. X.: P. IV: P. 224.

2.-BILCHICK and OKANE, - "Sulfanilamide in otitis medit in children". The latyngcscop2. February 194I. [. 197.

3.-BRAUN L., BIGLER J. - 'Sulfanilamide in the treatment of acute otitis media in children". A. J. of Disenses of Children, 1941: Vol. 62. N.? $3 ;$ P. $52 \mathrm{i}$

4.-GUILLERMIN at A. MIGAYRCN. -- "Complications diss otites observées au cours de lépidemiz de l'hiver 1930-1931". Les Ann. d'Ot. 1932. N." 1 ; P. 101 .

5.-HORAN and FRENCH. - "Sulphenamid in the treatment of acute mustoiditis". Britith Med. J. 5 de noviembre de 1938.

6.-KOPETZKY S. J. -- "Pumient otitis media, mastoiditis, sinus thrombosis and supputation of the pertrous pyramid". Arch. of Otolaryngole8\%. ]9+2. N.': 1: P. 115.

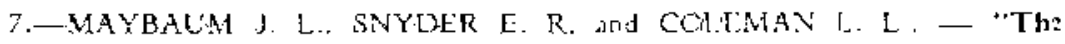
value of Sulfanilamide in Otogenous Infections with Spicili Reference of its Masking Effecl." J. A. M. A. 1939; V. l12: N. 25: P.. 2589

8.--I.EVADITI C. - "Rélixions sur le pa-sí, le present to l'avenir de la Chemiothrapie". Presse Med. 1938; $\lambda .70:$ P. 572.

9.-NETER, E., F. NEUBURGER. -- "Ot'tis media adu mastoiditis in chi:den. Arth. of Otolatyngology. 19+2: Vol. 35: N." 4: P. 631.

10.-OMPREDAVNiF M. - "Quelques sspects du probléme mastoidien au couss

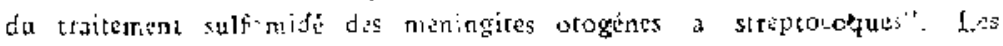
Ann. d'ot, $1939 ; \mathrm{N} .: 6 ;$ P. 584 